\title{
Association of Chemotherapeutic Drugs and Ecg Changes: A Review
}

\author{
Bhavna Anand, Ruchika Kalra* \\ Amity Institute of Physiotherapy, Amity University Noida, Uttar Pradesh, India.
}

*Corresponding Author: Ruchika Kalra, Amity Institute of Physiotherapy, Amity University Noida, Uttar Pradesh, India.

\section{Received Date: 13 August 2021 | Accepted Date: 04 September 2021 | Published Date: 11 September 2021}

Citation: B Anand, R Kalra. (2021) Association of Chemotherapeutic Drugs and Ecg Changes: A Review. Journal of Clinical and Laboratory Research 3(3); DOI:10.31579/2768-0487/044

Copyright: (ㄷ 2021 Ruchika Kalra. This is an open-access article distributed under the terms of the Creative Commons Attribution License, which permits unrestricted use, distribution, and reproduction in any medium, provided the original author and source are credited.

\begin{abstract}
:
Cancer is not only the challenging disease but the treatment is so the same. Chemotherapy is the treatment plan that is included as an essential treatment which increases the chances to live in serious cancer stages and their types but chemotherapy induced cardiac dysfunction is the life-threatening complications leading to electrophysiological dysfunctions presented at Electrocardiogram. Studies have presented that Chemotherapy is the cause around $5 \%$ of cardiac-toxicities and near $4 \%$ the reason of cardiac death in cancer. This study aims to review the literature behind the effect of chemotherapy on the electrocardiogram and its alterations see at various stages and types of cancer. The research literature was extracted the data from Google scholars, PubMed, Medline, and Cochrane. Various alterations on ECG parameters that were QTc prolongation, abnormal ventricular repolarization, increased heart rate, QRS complex abnormalities and the severity to the disease was seen in the increased in stage of cancer as early the cardiac toxicity was noticed and delayed in early cancer diagnosis.

Keywords: chemotherapy; cancer; electrocardiogram
\end{abstract}

\section{Introduction:}

With a newer drug development in chemotherapy in last twenty years has led to better survival and life expectancy of patients with cancer. At the same time, the adverse effects of the drugs are dreadful. Early recognition of these effects can prevent the associated pathologies. Cardiac side effects can be monitored using several tolls such as Electrocardiogram, Echocardiography, Coronary angiography, Ventriculography and cardiac MRI [1]. These techniques help in identification of subclinical heart damage [2]. Cardiac biomarkers such as BNP and NT pro BNP and ECG help in identification before clinical symptoms of heart failure, chronic coronary syndrome or myocardial infarction. Moreover, the symptoms if correlated within time span helps in prevention of cardiotoxicities.

The purpose of this search is to review in detail, the association of chemotherapeutic drugs with ECG changes. Also, studies have shown that ECG is the simplest form of examination that can be quickly performed within a duration of 3 minutes and provides the detailed information on cardiotoxicities. Some of the changes that can be noticed; for example, broad $\mathrm{P}$ wave lasting for more than $120 \mathrm{~ms}$, QT prolongation with interval of $>500 \mathrm{~ms}$. Also, presence of multiple atrial ectopic beats post cessation of chemotherapy [3].

Moreover, ECG recording is just not confined with hospitalization, there are ECG portable monitor with single or two lead are also available for monitoring at home. Nowadays electronic media usage, devices, smart watch smart phones, Holter ECG for 24 hours are also gave for an indication of cardiovascular manifestation. Hence forth, there is a need to carry on ECG before starting chemotherapy, to get a suitable baseline recording that can be related to post treatment measurements.

\section{ECG changes with different chemotherapeutic drugs}

\section{Anthracyclines:}

Used for the treatment of leukemias, Lymphomas, breast cancer and solid tumors in pediatric population. Doxorubicin persists an effect on development of dilated cardiomyopathy which is irreversible. Also, incidence of $5-8 \%$ is observed with daunorubicin combination of 450 $\mathrm{mg} / \mathrm{m}^{2}[4]$.

In a study 48 hours of monitoring of patients with Holter ECG, immediately infused doxorubicin infusion had shown paroxysmal fibrillation of atria at a rate of $0.3 \%$ [5]. Monitoring of ECG at each visit has shown $6 \%$ incidence of this arrythmia with the continuation of chemotherapy [6].

Detection rate of $56.6 \%$ with cardiac dysfunction had an integrated implantable defibrillator. Also, $73.9 \%$ cases had an incidence of ventricular tachycardia as compared without non-ischemic cardiomyopathy without anthracyclines [7]. Anthracycline induced ventricular arrythmia of premature contractions of ventricle [8]. 
Administration of dexrazoxane with epirubicin has shown QT interval decreased.

Antineoplastic alkylating agents: Administration given before bone marrow transplantation. Rich of developing drug induced arrythmias is seen in melphalan including advanced age left atrium dilated over $33 \mathrm{u} / \mathrm{cm}^{2}$, ventricular systolic dysfunction of left side, with over cardiac arrythmias [9-10]. Busulfan has shown to develop atrial fibrillation with incidence of $6.4 \%$ used in combination with cyclophosphamide [11].

Cancer patients treated with alkylating agents should be monitored for fibrillation in a atrium with busulfan and melphalan. Moreover, structural abnormalities developing leading to ventricular arrythmias with phosphamide and cyclophosphamide [3].

\section{Anti HER 2 Agents:}

Trastuzumab has an incidence of $1.2 \%$ of atrial fibrillation with administration in over 8000 patients has shown [12]. A long-term effect of trastuzumab in which cardiac toxicity was seen after 6 months and 12 months reported heart failure [13].

When anthracycline and taxanes are administered with trastuzumab has shown significant decrease in LVEF in around $1 \%$ [14].

Moreover, use of paclitaxel with trastuzumab post anthracycline and cyclophosphamide shown. $4 \%$ heart failure and decrease in LVEF below $50 \%$ was seen [15].

$10 \%$ asymptomatic decease in LVEF in 2 patients when trastuzumab was administered in elderly 22 patients [16].

Trastuzumab- emtansine (T-DM1) is the second line of treatment did not cause any cardiovascular events [17]. Lapatinib is a safer as it rarely causes left ventricular dysfunction than trastuzumab [18].

\section{Tyrosine kinase inhibitors:}

These are new drugs of chemotherapy and do not cause any structural abnormalities but prolongation of QT interval which further induces ventricular arrythmias as such as torsade.

Britten tyrosine kinase inhibitors such as Ibrutinib administration in chronic lymphocytic leukemias and mantle cells lymphoma [3]. When ibrutinib compared with other placebo showed incidence of atrial fibrillation is associated with ibrutinib as well as it an anti-platelet agent, with induces increased risk of bleeding. Moreover, antivitamin $\mathrm{K}$ use is discouraged in this category patients [19]. Ibrutinib induces risk of ventricular tachycardia, but does not prolong QTc interval [20].

\section{Anti-microtubule agents:}

Paclitaxel administration has led to high grade atrioventricular block in 2 patients out of 140 who required pacemaker implantation [21].

\section{Immunomodulating Agents:}

Thalidomide is administered in multiple myeloma that has leads to bradyarrhythmia's of different kinds of atrioventricular block [22]. Also, Thalidomide induces atrial fibrillation with incidence of $4.7 \%$ versus $3.7 \%$ in placebo healed aim [23]. Immunomodulators like lenalidomide is used in multiple myeloma and myelodysplastic syndrome which has been incidence of $7.6 \%$ to $4 \%$ in inducing supraventricular arrythmias used in combination with dexamethasone [24].

\section{Amsacrine:}

Used for acute myeloid leukemia and has similar effect electrophysiologically as anthracycline. It leads to atrioventricular arrythmias + QT prolongation [25]. Hydro-electrolytic imbalance are also seen with administration of amsacrine which eventually led to arrythmias [26].

\section{Trisenox (Arsenic trioxide):}

It has an excitatory action with activation of ATP dependent potassium channel and inhibits fast and slow potassium channel. This is the process of QT prolongation with concomitant and risk of torsade de pointes [3]. $38 \%$ patients treated with trisenox develop QT prolongation of more than $450 \mathrm{~ms}$ and $27 \%$ more than $500 \mathrm{~ms}$.

\section{Conclusion:}

Chemotherapeutic drugs are improving life expectancy functional status and quality of life in cancer survivors. But the newer development is leading to profound cardio toxicities. Therefore, it is a need that in clinical practice, ECG monitoring which takes 3 minutes should be carried out at baseline, post phase of treatment. Moreover, whenever any cardiovascular manifestation or symptoms are noticed these non- invasive diagnostics should be performed and monitored regularly to avoid dreadful adverse effects on the cardiac function.

\section{References:}

1. Tan LL, Lyon AR. (2018). Role of biomarkers in prediction of cardiotoxicity during cancer treatment. Current treatment options in cardiovascular medicine. 20(7): 1-4.

2. Mocan M, Mocan Hognogi LD, Anton FP, Chiorescu RM, Goidescu CM, Stoia MA, Farcas AD. (2019). Biomarkers of inflammation in left ventricular diastolic dysfunction. Disease Markers.

3. Spînu Ş, Cismaru G, Boarescu PM, Istratoaie S, Negru AG, Lazea C, Căinap SS, Iacob D, Grosu AI, Saraci G, Burz C. (2021). ECG Markers of Cardiovascular Toxicity in Adult and Pediatric Cancer Treatment. Disease Markers.

4. Doxorubicin, "FDA package insert,"

5. Kilickap S, Barista I, Akgul E, Aytemir K, Aksoy S, Tekuzman G. (2006). Early and late arrhythmogenic effects of doxorubicin. Journal of Clinical Oncology. 24(18s):18587.

6. Spînu Ş, Cismaru G, Boarescu PM, Istratoaie S, Negru AG, Lazea C, Căinap SS, Iacob D, Grosu AI, Saraci G, Burz C. (2021). ECG Markers of Cardiovascular Toxicity in Adult and Pediatric Cancer Treatment. Disease Markers.

7. Mazur M, Wang F, Hodge DO, Siontis BL, Beinborn DS, Villarraga HR, Lerman A, Friedman PA, Herrmann J. (2017). Burden of cardiac arrhythmias in patients with anthracyclinerelated cardiomyopathy. JACC: Clinical Electrophysiology. 3(2):139-150.

8. Raabe NK, Storstein L. (1991). Cardiac arrhythmias in patients with small cell lung cancer and cardiac disease before, during and after doxorubicin administration an evaluation of acute carditoxicity by continuous 24-hour Holter monitoring. Acta Oncologica. 30(7): 843-846.

9. Singla A, Hogan WJ, Ansell SM, Buadi FK, Dingli D, Dispenzieri A, Gastineau DA, Gertz MA, Hayman SR, Inwards DJ, Johnston PB. (2013). Incidence of supraventricular arrhythmias during autologous peripheral blood stem cell transplantation. Biology of blood and marrow transplantation. 19(8):1233-1237.

10. Longhi S, Quarta CC, Milandri A, Lorenzini M, Gagliardi C, Manuzzi L, Bacchi-Reggiani ML, Leone O, Ferlini A, Russo A, Gallelli I. (2015). Atrial fibrillation in amyloidotic cardiomyopathy: prevalence, incidence, risk factors and prognostic role. Amyloid. 22(3):147-155.

11. Ulrickson M, Aldridge J, Kim HT, Hochberg EP, Hammerman P, Dube C, Attar E, Ballen KK, Dey BR, McAfee SL, Spitzer TR. (2009). Busulfan and cyclophosphamide (Bu/Cy) as a preparative regimen for autologous stem cell transplantation in patients with non-Hodgkin lymphoma: a single-institution 
experience. Biology of Blood and Marrow Transplantation. 15(11):1447-1454.

12. Yuan M, Tse G, Zhang Z, Han X, Wu WK, Li G, Xia Y, Liu T. (2018). The incidence of atrial fibrillation with trastuzumab treatment: A systematic review and meta-analysis. Cardiovascular therapeutics. 36(6):12475.

13. Pivot X, Suter T, Nabholtz JM, Pierga JY, Espie M, Lortholary A, Khayat D, Pauporte I, Romieu G, Kramar A, Fumoleau P. (2015). Cardiac toxicity events in the PHARE trial, an adjuvant trastuzumab randomised phase III study. European Journal of Cancer. 51(13):1660-1666.

14. Dang C, Fornier M, Sugarman S, Troso-Sandoval T, Lake D, D'Andrea G, Seidman A, Sklarin N, Dickler M, Currie V, Gilewski T. (2008). The safety of dose-dense doxorubicin and cyclophosphamide followed by paclitaxel with trastuzumab in HER-2/neu overexpressed/amplified breast cancer. Journal of clinical oncology. 26(8):1216-1222.

15. Kelly H, Kimmick G, Dees EC, Collichio F, Gatti L, Sawyer L, Ivanova A, Dressler L, Graham ML, Carey LA. (2006) Response and cardiac toxicity of trastuzumab given in conjunction with weekly paclitaxel after doxorubicin/cyclophosphamide. Clinical breast cancer. 7(3):237-243.

16. Militello L, Carli P, Spazzapan S, Lestuzzi C, Miolo G, Scalone S, Veronesi A, Crivellari D. (2011). Safety of adjuvant trastuzumab $(\mathrm{T})$ in elderly patients with breast cancer. Journal of Clinical Oncology. 29(27s):282.

17. Krop IE, Suter TM, Dang CT, Dirix L, Romieu G, Zamagni C, Citron ML, Campone M, Xu N, Smitt M, Gianni L. (2015). Feasibility and cardiac safety of trastuzumab emtansine after anthracycline-based chemotherapy as (neo) adjuvant therapy for human epidermal growth factor receptor 2-positive earlystage breast cancer. Journal of clinical oncology. 33(10):1136.

18. Medina PJ, Goodin S. (2008). Lapatinib: a dual inhibitor of human epidermal growth factor receptor tyrosine kinases. Clinical therapeutics. 30(8):1426-1447.
19. Wiczer TE, Levine LB, Brumbaugh J, Coggins J, Zhao Q, Ruppert AS, Rogers K, McCoy A, Mousa L, Guha A, Heerema NA. (2017). Cumulative incidence, risk factors, and management of atrial fibrillation in patients receiving ibrutinib. Blood advances. 1(20):1739-1748.

20. A. Guha, M. H. Derbala, Q. Zhao et al. (2018). "Ventricular arrhythmias following ibrutinib initiation for lymphoid malignancies," Journal of the American College of Cardiology, 72(6): 697-698.

21. Rowinsky EK, McGuire WP, Guarnieri T, Fisherman JS, Christian MC, Donehower RC. (1991). Cardiac disturbances during the administration of taxol. Journal of Clinical Oncology. 9(9):1704-1712.

22. Fahdi IE, Gaddam V, Saucedo JF, Kishan CV, Vyas K, Deneke MG, Razek H, Thorn B, Bissett JK, Anaisse E, Barlogie B. (2004). Bradycardia during therapy for multiple myeloma with thalidomide. The American journal of cardiology. 93(8):10521055.

23. Rajkumar SV, Rosiñol L, Hussein M, Catalano J, Jedrzejczak W, Lucy L, Olesnyckyj M, Yu Z, Knight R, Zeldis JB, Bladé J. (2008). Multicenter, randomized, double-blind, placebocontrolled study of thalidomide plus dexamethasone compared with dexamethasone as initial therapy for newly diagnosed multiple myeloma. Journal of clinical oncology: official journal of the American Society of Clinical Oncology. 26(13): 2171.

24. Lenalidomide, "FDA package insert".

25. Guglin M, Aljayeh M, Saiyad S, Ali R, Curtis AB. (2009). Introducing a new entity: chemotherapy-induced arrhythmia. Europace. 11(12):1579-1586.

26. Arlin ZA, Feldman EJ, Mittelman A, Ahmed T, Puccio C, Chun HG, Cook P, Baskind P, Marboe C, Mehta R. (1991). Amsacrine is safe and effective therapy for patients with myocardial dysfunction and acute leukemia. Cancer. 68(6):1198-1200.
This work is licensed under Creative Commons Attribution 4.0 License
To Submit Your Article Click Here: Submit Manuscript

DOI: $10.31579 / 2768-0487 / 044$
Ready to submit your research? Choose Auctores and benefit from:

fast, convenient online submission

$>$ rigorous peer review by experienced research in your field

$>$ rapid publication on acceptance

$>$ authors retain copyrights

$>$ unique DOI for all articles

$>\quad$ immediate, unrestricted online access

At Auctores, research is always in progress.

Learn more auctoresonline.org/journals/journal-of-clinical-andlaboratory-research 